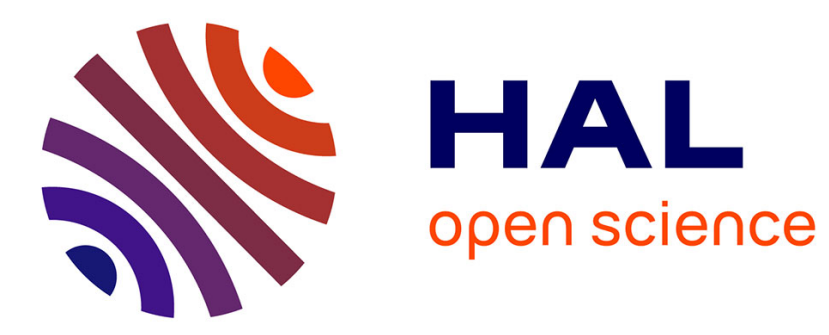

\title{
Maria Gravari-Barbas. 2020. Le Patrimoine mondial. Mise en tourisme, mise en images
}

Isabelle Brianso

\section{To cite this version:}

Isabelle Brianso. Maria Gravari-Barbas. 2020. Le Patrimoine mondial. Mise en tourisme, mise en images. Culture et Musées, 2021, pp.236-239. 10.4000/culturemusees.5933 . hal-03158810

\section{HAL Id: hal-03158810 \\ https://hal.science/hal-03158810}

Submitted on 7 Jan 2022

HAL is a multi-disciplinary open access archive for the deposit and dissemination of scientific research documents, whether they are published or not. The documents may come from teaching and research institutions in France or abroad, or from public or private research centers.
L'archive ouverte pluridisciplinaire HAL, est destinée au dépôt et à la diffusion de documents scientifiques de niveau recherche, publiés ou non, émanant des établissements d'enseignement et de recherche français ou étrangers, des laboratoires publics ou privés. 
C ULTURE Culture \& Musées

$\& \overline{\text { MuSÉEs }}$ Muséologie et recherches sur la culture

$37 \mid 2021$

Les collections patrimoniales ont-elles un avenir?

\section{Maria Gravari-Barbas. 2020. Le Patrimoine mondial. Mise en tourisme, mise en images}

Isabelle Brianso

\section{(2) OpenEdition}

1 Journals

Édition électronique

URL : https://journals.openedition.org/culturemusees/5933

DOI : 10.4000/culturemusees.5933

ISSN : 2111-4528

Éditeur :

Avignon Université, UGA Éditions/Université Grenoble Alpes

Édition imprimée

Date de publication : 1 juin 2021

Pagination : 236-239

ISSN : 1766-2923

Ce document vous est offert par Avignon Université

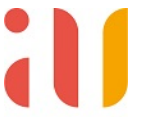

AVIGNON

UNIVERSITE

Référence électronique

Isabelle Brianso, « Maria Gravari-Barbas. 2020. Le Patrimoine mondial. Mise en tourisme, mise en images », Culture \& Musées [En ligne], 37 | 2021, mis en ligne le 01 juin 2021, consulté le 07 janvier 2022. URL : http://journals.openedition.org/culturemusees/5933 ; DOI : https://doi.org/10.4000/ culturemusees.5933

Culture \& Musées 
Maria Gravari-Barbas. 2020.

\title{
Le Patrimoine mondial.
}

\section{Mise en tourisme, mise en images}

\author{
Isabelle Brianso \\ Avignon Université - Centre \\ Norbert Elias
}

\begin{abstract}
Référence(s): Gravari-Barbas (Maria) (dir.). 2020. Le Patrimoine mondial. Mise en tourisme, mise en images. Paris : L'Harmattan (Géographie et cultures).
\end{abstract}

Cet ouvrage collectif, sous la direction scientifique de Maria Gravari-Barbas (Irest, Université Paris 1), étudie les images de sites touristiques comme fabrique visuelle de la patrimonialisation dans le cadre d'un projet de recherche financé par l'ANR'. Partant du postulat que les images ne sont pas neutres - notamment de la part de ceux qui les produisent et qui les font circuler dans des arènes privées (visiteurs, habitants, touristes), marchandes (acteurs touristiques) ou économiques (promoteurs) -, ces dernières mettent en scène et donnent à voir des éléments matériels, immatériels et naturels du patrimoine mondial (monuments, sites, paysages, danses, etc.). Cette diversité de productions iconiques construit des représentations touristiques mondialisées qui rendent les lieux désirables et attractifs

1. Projet ANR "Patrimondi »(2015-2019), en ligne: https://patrimondi.hypotheses.org/equipe (consulté le 19 janvier 2021). grâce à la chaîne "image, imaginaire touristique, destination touristique " (p. 8). Cet ouvrage de géographie culturelle s'appuie sur un corpus d'images (affiches, photographies, cartes postales) soigneusement identifiées et collectées dans le monde (Cambodge, Maroc, Canada, Chine, Argentine, France) par une équipe interdisciplinaire de chercheurs en tourisme, également auteurs des textes publiés. II questionne, par ailleurs, les dynamiques touristiques dont font l'objet ces images lorsqu'elles sont produites et diffusées sur différents supports médiatiques (guides de voyage, réseaux sociaux, dispositifs de médiation, cartes postales, brochures, etc.).

Ainsi, les neuf articles (hors introduction et conclusion) rassemblés dans cet ouvrage collectif étudient les relations entre images, patrimondialisation et mise en tourisme à partir d'études de cas géographiques, à savoir, cinq biens patrimoniaux labélisés par l'Unesco ou bénéficiant d'un accord 
international. L'objectif scientifique est d'extraire des lignes directrices sur la façon dont les images interagissent dans le processus de patrimonialisation et la mise en tourisme des sites inscrits par l'Unesco.

Les trois premiers textes se penchent sur le site emblématique d'Angkor (Cambodge) comme terrain d'études à l'élaboration de plusieurs corpus médiatiques (photographies, récits illustrés Le Tour du monde, expositions) à destination de visiteurs éclairés en contexte colonial ou de touristes arrivés en masse à l'ère contemporaine. En effet, dès l'époque coloniale, sous le protectorat français (1863-1953), les temples d'Angkor se transforment en véritable laboratoire de la patrimondialisation (Chau Sun \& Gravari-Barbas ; Sirven) en raison des premiers voyageurs français qui y voient des monuments et des objets dignes d'être montrés. De la création du Musée indochinois en 1880 à Paris (Trocadéro) aux grandes Expositions (internationales, universelles et coloniales) du début du $x x^{e}$ siècle en France, les visiteurs se pressent par milliers pour découvrir les moulages et les reconstitutions à échelle 1 . Cette première vague touristique s'accompagne d'une seconde à la suite de l'inscription du site sur la liste du patrimoine mondial (1991), faisant ainsi basculer Angkor à l'ère du tourisme de masse par la production iconique d'un lieu-monde, au sens d'un site universel fabriqué par et pour le tourisme.

L'article de Picon-Lefebvre étudie les représentations photographiques du site dans les guides touristiques contemporains selon une méthodologie, quantitative et qualitative, qui lui permet de classer trois types de photographies, puis de caractériser trois registres visuels (icône, métonymie, exotisme) autour de trois temples particulièrement prisés par les guides touristiques (Angkor Vat, Bayon, Ta Prohm). L'imaginaire ainsi véhiculé par les photographies de ces guides touristiques traduit encore aujourd'hui un cadre fantasmé de l'exotisme angkorien (jungle, moines, villages, touristes épars et éduqués), bien qu'il soit désormais très éloigné de la réalité touristique du $x \mathrm{xl}^{\mathrm{e}}$ siècle, notamment du fait de la surfréquentation du parc d'Angkor et de l'arrivée massive de nouveaux touristes asiatiques dont les Chinois. Cet imaginaire iconique continue néanmoins de circuler activement par des publications réactualisées des principaux éditeurs de guides touristiques français et internationaux (Lonely Planet, Eyewitness Travel, etc.).

La seconde étude de cas réunit deux articles consacrés au quartier du VieuxQuébec (Canada) à partir d'approches, empiriques et réflexives, complémentaires. Gravari-Barbas et Boukhris étudient les processus iconiques et architecturaux à l'œuvre d'une mise en tension urbaine orchestrée par les enjeux du tourisme à partir de deux lieux emblématiques de la ville: d'une part le Château Frontenac et d'autre part la Basse-Ville (la place Royale, le Petit Champlain). Elles montrent comment le Château Frontenac est passé d'hôtel de villégiature pour touristes éclairés à monument historique iconique relayé par les guides touristiques de voyage (19 guides et 221 images étudiées). Elles soulignent le pouvoir des médias sociaux numériques dans la construction de la performativité des images qui prescrit aux touristes la manière de visiter et de regarder le site, notamment pour profiter de la vue panoramique sur le Saint-Laurent. À l'inverse, elles montrent comment le projet d'aménagement (restauration/ reconstruction) de la place Royale a sculpté une hybridation urbaine selon un stéréotype spatial construit à partir d'un projet de promoteur touristique figeant la « maison française du XvIII siècle » du Vieux-Québec selon une vision pittoresque du lieu. Le contre-exemple à mettre en perspective à la place Royale est, selon Boukhris, la rénovation d'un ancien quartier industriel insalubre, autrefois habité par des ouvriers et des immigrés anglo-saxons, au pied du Château Frontenac (Basse-Ville). Ainsi, la fabrique patrimoniale du Petit Champlain repose selon l'auteur sur deux points de vue ambivalents quant au processus de patrimonialisation de cet hyper-centre urbain inscrit par l'Unesco (1985): d'un côté, la rénovation patrimoniale du Petit Champlain reposerait, selon Boukhris, sur le concept d'hyperréalité au sens d'une "production factice d'artefacts supposés représenter parfaitement la réalité » (p. 105); de l'autre, le projet de rénovation porté par deux acteurs privés (architecte, industriel) s'inscrirait au contraire dans le réel, au sens d'une authenticité patrimoniale retrouvée. La mise en tension de ces projets 
de rénovation est discutée par les auteurs à partir de ces deux lieux touristiques du Vieux-Québec selon une double lecture critique. Tout d'abord, les auteures questionnent les postures professionnelles de ces acteurs privés qu'ils projettent sur l'espace patrimonial, puis elles analysent de manière détaillée la construction esthétique d'un décor patrimonial scénarisé par et pour le tourisme, dont la documentation iconique est issue d'images circulant dans l'arène sociale. L'article pointe quelques constats, comme un mode de vie passé mis en scène dans l'espace patrimonial à partir d'aquarelles de James Pattison Cockburn (1779-1847) et de canons architecturaux en provenance du continent européen.

La troisième étude de cas porte sur la ville de Marrakech, ou comment ce lieu est devenu une destination touristique. À partir d'un corpus de références iconiques (guides de voyage, magazines spécialisés, sites institutionnels, photographies, cartes postales), les trois auteurs (Carabelli, Madoeuf, Tebbaa) analysent les topos de Marrakech. Ils identifient trois types d'images qui circulent activement dans la littérature touristique : tout d'abord la vue patrimoniale issue du modèle urbain colonial, puis l'icône mythique incarnée par la place Jemaa el-Fna grâce à sa double inscription Unesco (convention 1972 convention 2003) et, enfin, Marrakech comme cité hydraulique (jardin, palmeraie, réseau d'eau, Atlas). Les auteurs observent une fabrique de l'imagerie de Marrakech diversifiée au sens où la ville ancre son iconographie selon une approche kaléidoscopique qui convoque, certes, certains lieux patrimoniaux, mais surtout un mode de vie local. En d'autres termes, la ville n'est pas associée à un objet phare auquel elle puisse être identifiée de manière univoque, comme c'est le cas pour d'autres villes-mondes (Paris - tour Eiffel, Rome-Colisée, Athènes-Parthénon), mais par un ensemble d'objets interchangeables, voire superposables. Selon les auteurs, le fait d'" habiter la ville ", c'est-à-dire d'y séjourner au quotidien, a changé le rapport à la ville, notamment au tournant colonial puis à l'arrivée de personnalités internationales dès l'indépendance du Maroc (1957). Ces dernières ont ainsi transformé Marrakech en un lieu attractif et performant pour le tourisme, offrant à ses visiteurs des lieux d'exception portés par un néo-orientalisme marocain fantasmé (grands hôtels, riads, maisons d'hôtes) et impulsant un phénomène original dit de "réverbération " (p. 143-144) que les auteurs associent à la production d'une mosaïque d'images réfractées de Marrakech.

La quatrième étude de cas s'inscrit dans une réflexion thématique à partir de deux terrains géographiquement éloignés (France, Chine) mais qui interrogent l'émergence du patrimoine industriel en vue d'un développement touristique porté par les acteurs du territoire. Ces deux articles retracent une historiographie de la mise en tourisme de ce patrimoine ordinaire et marginalisé, l'un s'appuyant sur l'exemple des concessions occidentales de la ville de Tianjin, en Chine (Lu \& Mengin), l'autre étudiant le bassin minier du Nord de la France comme nouvelle fabrique patrimoniale et iconique (Fagnoni). Des lieux de vie ordinaires qui ont acquis une reconnaissance exceptionnelle (label Unesco), voire un intérêt inattendu (schéma directeur) eu égard à l'histoire sociale et politique du lieu. Les auteurs soulignent les dynamiques iconiques générées par le tourisme et le territoire en vue d'un ré-enchantement de la mémoire industrielle, technique et artisanale, ou comment ces territoires sont instrumentalisés pour la construction patrimoniale d'une mise en désir touristique et iconique.

La cinquième et dernière étude de cas analyse les dynamiques globalisées d'images du tango argentin. Ces dernières sont principalement figées en stéréotypes iconiques grâce à la figure du couple érotisé et de marqueurs identitaires de l'espace urbain (Buenos Aires et certains de ses quartiers) dans les guides de voyage et les autres supports visuels (affiches, photographies, etc.). Les auteurs (Cominelli, Jacquot, Salin) développent une méthodologie de recherche, empirique (entretiens, observations, analyse de corpus) et multi-située (Argentine, France), tournée d'une part vers les praticiens de tango, d'autre part sur la collecte d'images touristiques et promotionnelles construites en vue de produire du désir (sensualité) et de faire connaître un événement (festival). Les auteurs observent et pointent des hybridations mondialisées, notamment via les festivals de tango dans le monde, 
qui révèlent quatre registres selon le croisement indiciel "lieu » et " activité ». Ces registres d'hybridation reposent, selon les auteurs, sur l'invitation au voyage, la balnéarisation, l'altérisation et la fusion de pratiques et d'objets. En somme, une géographie iconique et ambivalente de l'objet culturel « tango » qui interroge les représentations sociales et l'imagerie de cette pratique artistique inscrite sur la liste du patrimoine culturel immatériel de I'Unesco.

Pour conclure, cet ouvrage analyse les constructions iconiques et les imageries globalisées liées à la mise en tourisme de lieux-mondes (sites culturels ou villes) et d'expressions artistiques exportées comme la danse. Les cinq biens culturels étudiés par les auteurs présentent un attrait historique, spatial et médiatique légitime pour interroger les mécanismes processuels et mondialisés de l'image patrimonialisatrice. Cette fabrique patrimoniale par les images fait ainsi dialoguer la géographie culturelle et les sciences de l'information et de la communication grâce aux terrains identifiés et aux corpus analysés, ce qui donne à l'ouvrage un intérêt théorique et méthodologique selon des points de vue complémentaires quant aux représentations mondialisées du patrimoine circulant dans les sphères sociales et touristiques. Par ailleurs, l'étude interdisciplinaire de ces objets culturels du patrimoine mondialisé fait écho à de nombreux travaux issus des sciences de l'information et de la communication, mais aussi à la façon dont cette discipline les observe et les analyse en recherche. Néanmoins, certains travaux fondateurs (Jacobi, 2017 ; Davallon, 2016) et récents (Brianso, 2017) produits dans ce champ disciplinaire auraient mérité d'être référencés dans les neuf articles.

\section{Bibliographie}

Brianso (Isabelle). 2017. « L'expérience de visite des touristes chinois à Versailles: entre stéréotype et représentations ". Communication \& Langages, 191, p. 51-65.

Davallon (Jean). 2016. "Penser le patrimoine selon une perspective communicationnelle ». Sciences de la société, 99, p. 15-29.

Jacobi (Daniel) (dir.). 2017. Communication \& Langages, 191, "Homo Turisticus. La délectation culturelle à l'ère du tourisme de masse $"$.

Auteure

Courriel : isabelle.brianso[at]univ-avignon.fr 